\title{
The effect of integration electronic mind maps into Arabic language vocabulary's lecture on achievements of fifth-grade students in Jordan
}

\author{
Prof. Akram M. Alomari ${ }^{1}$, Dr. Mohamad E. Al horani ${ }^{2}$ \\ ${ }^{1}$ Yrmouk University, School of Educational Technology \\ Irbid, Jordan \\ ${ }^{2}$ School of Education, University of Science and Technology Abu Dhabi \\ Abu Dhabi, United Emirate
}

\begin{abstract}
:
The study was conducted to investigate the integration of electronic mind map within the Arabic vocabulary instruction for fifth-grade students at Jordan. The sample included two classes chosen by the available method from the fifth grade classes in two schools in northern Jordan. One of the classes (29 pupils) whom represented the experimental group; its members studied using the strategy of Electronic Mind map. The other class (30 pupils) represented the control group. The researchers used an achievement test, as well as a collective interview conducted with the experimental group after the posttest. The results revealed that the computerized mind map reinforced students' educational accomplishment in Arabic vocabulary, increased their concentration and created the instructive process more interactive fascinating and gratifying and continue to learn. The study suggested the acceleration of the integration of mind maps in the Arabic language in several education stages. encourage the use of internet in schools particularly within the second stage and also to require advantage of specialists within the field of educational technology to attain the highest-quality lecturers.
\end{abstract}

Keywords: Electronic Mind-maps, Arabic Language, Vocabulary learning, Student Learning. Jordan

\section{Introduction}

Vocabulary generally and Arabic vocabulary precisely are among the most needful skills a learner should possess. It is worth mentioning that learning depends on many processes, the most necessity one is the comprehension of vocabulary, which becomes a prerequisite for learning a language (Brown, 200), and the most important which dominates all language skills. According to Al-Qahtani (2015), vocabulary remains a linguistic requirement that an individual needs to read, write and communicate with others. Nation (2011) added, the process of learning vocabulary remains an urgent need for instruction. It is intellectual skills associated with the educational process and can effects the academic accomplishment and success in varied study subjects. Consistent with Atay \& Ozbulgan (2007 teaching pupils the vocabulary of a language with an explicit strategy should be used, so they can employ these words in their lives. Furthermore, learning Arabic vocabulary requires a teaching strategy that will guarantee a learner to increase the capability of his memory and his level of motivation. The Mind Map that can be developed through the web and computer is one of those techniques that can improve the learning of Arabic vocabulary, especially as education in Jordan right now faces many challenges in integrating technology into Arabic language classes. The most important challenges are traditional teaching style, and the indifference to change, despite the availability of computer labs and the internet in most schools that make use of electronic mind maps an opportunity to change and develop strategies for teaching Arabic. The Electronic Mind Map can be a pedagogical technique that can be combined with the traditional method of teaching Arabic vocabulary, so that the student can interact with the texts and identify the main and secondary ideas and place them on the map using images and shapes to represent their sub-sections. This process will create intellectual images and visual perceptions of the vocabulary items that might help in recalling them when needed (Moore \& Lo, 2008; Lipson \& Wixson, 2009). When Mind Maps 
emerged, the standard form of the Mind Map was drawn manually (Dara, 2010). However, with the arrival of Mind Map software packages, similar steps were employed in the standard Mind Map. The difference is the software packages which provide special drawing tools such as clip art images shapes and colors which will be simply inserted (Elabady \& Jradat, 2015; Boyson, 2009). This will engage learners by making color branches driven from the primary idea which might be amended or transferred whereas pictures and symbols are added in an exact means that needs automatic thinking within the creation of ideas and knowledge (Abdul baset, 2016). In line with what Ruffini ( 2008) and Supermex (2005) mentioned, the sensible use of electronic mind maps act as a graphical interface that helps to free specific ideas and show the complicated interrelations between key ideas and meant content in a precise nonlinear visual structure, this will improve the learner's memory and vigorously promoting active learning especially once written information is retrieved (Al jaser, 2017; Nodoushan \& Maibodi, 2017; kaveh \& Rassaei, 2016; Carol, 2015; Toi, 2009). Such strategy may enhance learners' ability to perceive the vocabulary of the text utilizing his stored previous information. The positive effects of electronic mind maps have been supported by many researches in developing English vocabulary.(Al Jaser, 2017; Hamdan \& Alharbi, 2017; Bahadori \& Gorjian 2016; Al-otaibi, 2016; Al-badwoi, 2015; leyden, 2014;Rabeka, 2014; O'reilly, 2015). In Jordan, the researchers did not find a single study that dealt with the effect of Electronic Mind Maps on comprehension Arabic vocabulary, not even in understanding the language.

\subsection{Research Problem}

It is evident that Jordanian students have low success rate in Arabic language, as illustrated by the final Secondary Certificate Examination in Jordan, Perhaps, one of the fundamental reasons for the low success may be students having low comprehensive body of vocabulary, that is the most mental ability connected with achievement rate (Lee, 2006; Liach \& Gallego, 2009; Nong, Pham, \& Tran, 2006; Cobb \& Morris, 2004). There may be another source of the problem of teaching Arabic vocabulary, it is still influenced by traditional approaches in Arab education that impacts on student's low performance and surrounded a lasting result on Arabic slowness.
Hence, the aim is to dominate the newest teaching pedagogy by utilizing the Electronic Mind Map strategy. Researchers of this given study have selected the electronic mind mapping technique to search out what proportion would improve the Arabic vocabulary skills of fifth-grade students at Jordan. With this regard, the study addressed the subsequent question:

- Is there a significant difference at $(\alpha=0.05)$ between the mean scores of the experimental and control groups in the vocabulary test which, is attributed to the use of electronic mind maps in the teaching of Arabic language?

\subsection{Research Focus}

The present study aimed to investigate the use of Electronic Mind Maps blended with the Arabic Vocabulary traditional instruction, and objectively compare that with the traditional methodology of teaching. Therefore, The importance of this study was to deal with the variable electronic mind map technology, and its impact on improving the vocabulary of the Arabic, it's a teaching strategy which will contribute to the encouragement of academics in using fashionable techniques to unravel the students' weakness within the absorption of Arabic vocabulary In Jordan. There's hope that the finding of this study can contribute to additional understanding of the utilization of electronic mind maps in rising Arabic vocabulary accomplishment, and overcome the gap within the relevant literature because of the inadequacy of studies addressing the effectiveness of electronic mind maps for acquiring vocabulary in Jordan. In addition, it should capture the attention of decision-makers within the Ministry of Education to conduct workshops and offering training courses to develop the academic process by involving the use of the Electronic Map technique to enhance the educational level.

\section{Methodology}

\subsection{Research Design:}

This investigation objectively applied a quasiexperimental design with two groups; one was exposed to blended teaching strategy while the other group maintained the traditional teaching method. Both groups were exposed to pre test and post test that focused on their achievement in three major vocabulary skills (spelling, word recognition and vocabulary use). All treated participants objectively interviewed, then their 
responses were recorded, categorized and documented.

\subsection{Participants:}

Two male schools from the study community of first Irbid region in the north of Jordan were Intentionally selected. The choice was made based on the approval of school administrators and the availability of computer lab. One fifth graders' Arabic language class was randomly picked from each school; one class consisted of 29 male pupils was picked as experimental group, the other class (30 pupils) was assigned as the control group.

\subsection{Instruments and measures}

\section{Achievement Test}

Cited references related to the cognitive learning of Arabic and English vocabulary were considered (Othman, 2018; Al-jaser, 2017; Nodoushan \& Maibodi, 2017; Abdul Aziz \& Yamat, 2016; Aljarf, 2015; Bahadori \& Gorjian, 2016; Krasnic, 2011; Al water \& Al-Balhan, 2018; Gasrawi, 2015; Awad, 2013; Wafi, 2013). Content analysis of academic subjects (spelling, word recognition and vocabulary use) was carefully performed and specification table carefully extracted from the selected units was carefully prepared. accordingly, an achievement test was developed professionally to assess fifth-grade Jordanian students cognitive level of vocabulary knowledge, it consisted of 24 multiple choice items. The empirical test was validated with an acceptable reliability coefficient of 0.82 .

\subsection{Study plan}

This study used teacher guide that was prepared by the researchers with the help of Arabic teacher, the guide covers an overview of electronic Mind Maps strategy to teach the suggested unit and the time plan of teaching each lesson of the unit. After completing the preparation of the teacher guide, it was submitted to a group of reviewers to judge the formulation of objectives, teaching plans, and formatting lessons according to electronic mind maps, the teacher guide was submitted to a group of reviewers to evaluate the formulation of objectives, teaching plans and the coordination of lessons according to electronic mind maps. a preachievement test was conducted to the experimental and control groups. Before treatment begins, a meeting was held with the experimental group to give instructions to begin the experiment, then, the teacher and learners practiced lessons ten days before the formal experiment using electronic mind maps. The study began after practice, wherein each session, an introduction for the new topic was given to the whole class by using and presenting electronic mind maps. Then, students were instructed to work individually using the electronic mind maps that guided and supported them to facilitate their learning as follow: students were instructed to draw an image in the center of a sheet of paper to represent the main ideas of the lesson, then, students were instructed to draw out a series of curved thick lines from the Centre of the image, and to write one keyword on each branch, that is associated with the topic. Next, draw second level branches and connect them to the primary branches and draw third-level branches and connect them to the second branches, with some branches left empty on each students' mind map.

At the end of each session, the teacher instructed learners to stop using their computers, then assessed and evaluated their performances, including a brief discussion held with the whole class to ensure that students carefully processed the effectiveness of their learning. the postachievement test was applied after treatment.

\section{Results of Study}

To ensure that pupils of the two study groups had similar levels of Arabic language Vocabulary, the results of the pre-test were inputted into the Spss program, and extracted the mean averages, the standard deviations and the results of (T) test. (As shown in Table 1.)

\begin{tabular}{|c|c|c|c|c|c|}
\hline Groups & & $\begin{array}{c}M \\
\text { ean }\end{array}$ & $\begin{array}{l}S \\
. D .\end{array}$ & $T$ & $g^{S i}$ \\
\hline $\begin{array}{l}\text { Experimental } \\
\text { group }\end{array}$ & $9^{2}$ & $.14^{15}$ & $.26^{2}$ & \multirow[t]{2}{*}{ 54- } & \multirow[t]{2}{*}{$\begin{array}{r}0 . \\
131\end{array}$} \\
\hline $\begin{array}{l}\text { Control } \\
\text { group }\end{array}$ & $0^{3}$ & $.97^{15}$ & .73 & & \\
\hline
\end{tabular}

Results in table 1 show that the statistical significance value is 0.131 , which is greater than the level of statistical significance $\alpha=0.05$ ( $\mathrm{t}=$ $1.54, \mathrm{P}<0.05)$. Thus, both groups have similar levels of knowledge in Arabic Vocabulary.

Table 2, reveals a difference between the arithmetic means of the two groups in the posttest scores, in favor of the Electronic Mind Map strategy. To verify this result, t-test was conducted, and the results are presented in Table 2 . 
Table 2: t-test result

\begin{tabular}{|c|c|c|c|c|c|}
\hline Groups & & $\begin{array}{c}m \\
\text { ean }\end{array}$ & $\begin{array}{l}\text { S } \\
\text {.D. }\end{array}$ & $\mathrm{T}$ & $\mathrm{g}^{\mathrm{Si}}$ \\
\hline $\begin{array}{l}\text { Experime } \\
\text { ntal group }\end{array}$ & 9 & $.17^{18}$ & $\begin{array}{c}1 \\
.44\end{array}$ & \multirow[t]{2}{*}{$.04^{* 6}$} & \multirow[t]{2}{*}{$\begin{array}{r}0 \\
001\end{array}$} \\
\hline Control & 0 & $.97^{14}$ & $.51^{2}$ & & \\
\hline
\end{tabular}

Table (2) presents the results of t-test on post test scores $(\mathrm{t}=60.4, \mathrm{P}<0.05)$, This indicates that the electronic Mind Maps improved students' vocabulary achievement more than the control group..

\section{Discussion, Conclusion, and Implications}

This presented study was conducted to examine the effect of electronic mind maps in teaching fifth-grade Jordanian students Arabic language vocabulary. Results indicate that there was a statistically significant difference at the significance level of $(\alpha=05.0)$ between the achievement attributed to the method of teaching, in favor of using the electronic mind maps. Therefore, the electronic mind maps technique can be considered more effective than the traditional method when teaching Arabic language vocabulary.

The positive impact on the development of vocabulary comprehension may be attributed to the fact that the lessons use electronic mind maps program was the analysis of texts, the Identifying vocabulary and determining its isotopes on the principle of linking Sub-ideas and examples with their main ideas in a sequential and accessible way. The results of the interviews provided evidence that the members of the experimental group learned in a way that helped to accelerate learning and knowledge discovery faster during the drawing of Mind Map; as one of the interviewers said, " We have illustrated the basic concept and the main ideas and sub-ideas and we have done these activities our self...... Where the sub-ideas associated with the main ideas through drawing, colors and sensory things..., ". This work may have stored the material in Students' minds, as the brain learns better when using both left and right brain sides, and this is what mind maps do, combining written information with graphics and symbols. In addition, the use of Mind Maps consistently with Constructivism theory in the knowledge that depicts knowledge as an activity constructed and constructed by the learner.
The positive impact on the development of the comprehension of the Arabic vocabulary in the experimental group may be attributed to the fact that the lessons learned in the study used the Electronic Mind Maps program in which the texts were analyzed and the understanding of the main and sub-ideas was understood through the adoption of electronic mental maps based on the principle of linking sub ideas and examples with their origins in a concise and accessible manner. In addition to that, Electronic Mind Maps rely on images, shapes, and color used to create mind maps in a creative computer environment. And to represent the ideas placed in abstract words in a drawing based on the perception of the naughty brain words and figures of the left, and the images and colors of the right section ( Siriphanich \& Lohawiriyanon, 2010; Lamberski, 2014; Berg, 2011). Since there is agreement that the Mind Map works in the same way the brain works, its use stimulates the use of the naughty brain and arranges information in a way that helps the mind to analyze texts, arrange their thoughts, store and remember information; which helped develop the comprehension of their Arabic vocabulary.

When students of the experimental group were interviewed, most agreed that the Electronic Mind Map provided the students with an opportunity to learn the contents in the form of both verbal information and visual images, building links between words, connecting colors, symbols and pictures with words. As one interviewer said, " I was very relieved to have discovered the word myself and discovered words that give the same meaning and distinguish them with pictures and colors. .... It is a wonderful experience... I hope to circulate this experiment on all the subjects of the study."Another interviewer said."I have employed colors, images, symbols, pictures to highlight different word types, revised their sources which allowed me to remember the word by where I had learned it from... Because the connection between the source and vocabulary was built in my memory...".

Finally, The results of the presented study indicate that the electronic Mind Maps improved fifth-grade students' Arabic vocabulary achievement. The findings of this study agreed with the results of some previous studies, which revealed the good effect of mind mapping on English vocabulary learning in different countries (I.e. Karimi \& Heidari, 2015; Sahrawi, 2013; Bahadori \& Gorjian, 2016; Abdul Aziz \& Yamat, 
2016; Al Jarf, 2015; Buran \& Filukov, 2015), while this study revealed the positive effect of Electronic Mind Maps on Jordanian students learning Arabic vocabulary Language. As one interviewer said"... The Electronic Mind Map motivated us to continue using it for learning vocabulary at home...It's a really useful tool...we love it...". Another interviewer indicated." on behave of my colligates, we all wish that our teachers keep using this strategy...". Therefore, the results of this study suggest that Electronic Mind Mapping can be effective technology tools for learners, teachers, researchers, and curriculum designers, and therefore, this study may help researchers and scholars in the area of learning diverse aspects of Arabic language, conducting other analytical and experimental studies through the use of electronic mind mapping. This focused study also implies that the active use of Electronic Mind Mapping can make the presentation of vocabulary item connected to its clue all in one visualized picture, teachers should employ this strategy to teach Arabic vocabulary because it is more effective than traditional teaching methods, they can employ the use of electronic mind mapping to support students memorize vocabulary items in an convenient and pleasant way.

\section{References:}

[1] A. Abdul Aziz, H. Yamat, "The Use of Mind Mapping_Technique in Increasing Students' Vocabulary List,". Journal of Education and Social Sciences, (4), PP. 105-113, 2016.

[2] Abdul baset, H. M. "Digital Mind Maps: Their activities in education and learning,". E-Learning Journal, (12), PP. 89- 98, 2016.

[3] M. Al-Qahtani, "The Importance of Vocabulary in Language Learning and How to be taught, ". International Journal of Teaching and Education, 3 (3), PP. 22, 23-26, 2015.

[4] A. Al Jaser, "The effectiveness of using flipped classroom strategy in academic achievement and self-efficacy among education students of Princess". Noura Bint Abdulrahman University. Canadian Center of Science and Education, 10 (2), PP. 62- 74, 2017.

[5] R. Al-jarf, "A Model for Enhancing EFL Freshman Students' Vocabulary with Mind Mapping Software,". The Journal of Teaching English for Specific and
Academic Purposes, 3 (3), PP. 67- 77, 2015.

[6] N. Al water, E. Al-Balhan, "The Effectiveness of the E-mind Mapping Strategy for Sixth Grade Students' Achievement Level in Learning Arabic Vocabulary in Kuwait," The New Educational Review, PP. 115-125, 2018.

[7] R. Awad, "The Effect of Using Animation in Teaching English Vocabulary for 3rd Graders in Gaza Governmental Schools". (Unpublished MA Thesis). Al-Azhar University, Gaza, Palestine, 2013.

[8] G. Al-Otaibi, "The Effect of semantic mapping on student's vocabulary,". Arab World, English Journal, 7, PP. 279-294, 2016.

[9] A. S. Al-Badwoi, "Using E-mind mapping in learning at IBRIK College of applied sciences,". Global Journal of Computer Science and Technology, 11 (5), PP. 110 119, 2015.

[10] M. A. Aljaser, "The Effectiveness of Electronic Mind Maps in Developing Academic Achievement and the Attitude towards Learning English among Primary School Students,". International Education Studies, 10 (12), PP. 80, 2017.

[11] D. Atay, C. Ozbulgan, "Memory Strategy Instruction, Contextual Learning, and EDP Vocabulary Recall. Memory Strategy Instruction.", Contextual Learning, and EDP Vocabulary Recall. English for Specific Purposes, 26 (1), PP. 39-51, 2007.

[12] A. Buran, A. Filyakov, "Mind Mapping Technique in Language Learning," Procedia - Social and Behavioral Sciences, 206, PP. 215 - 218, 2015. [Online]. Available:

from:http://www.sciencedirect.com/science /article/pii/S1877042815051435

[Accessed: Dec 12, 2018].

[13] A. Bahadori, B. Gorjian, "The Role of Mind Mapping Software in Developing EFL Learner's Vocabulary at the PreIntermediate Level,". Journal of Applied Linguistics and Language Learning, 2 (1), PP. 8-16, 2016.

[14] H. D. Brown, "Teaching by principles: An interactive approach to language pedagogy," White Plains, NY, Longman. 2001. 
[15] T. Cobb, L. Morris, "Vocabulary profiles as predictors of the academic performance of TESL trainees," System, 32, PP. 75-87, 2004.

[16] P. Carol. "Using Mind-Mapping as a Tool to teach English Vocabulary for the Elementary Students," Bulletin of Chinese, 2015..

[17] C. Dara, "Hand Drawing Vs. Using Software Mind Mapping”. 2010. [Online]. Available:

http://www.isoftwarereviews.com/handdrawingvs- using-software-mind-mapping/ [Accessed: Sept 21, 2018].

[18] H. M. Elabady, Y. A. Jradat, "The Impact of using e-Mind Maps in developing reading comprehension in English among ninth-year basic students," Jordan Journal of Educational Sciences, 11 (4), PP. 469480, 2015.

[19] B. Gorjian, A. Bahadori, "The Role of Mind Mapping Software in Developing EFL Learner's Vocabulary at the PreIntermediate level," Journal of Applied Linguistics and Language Learning, 2, PP. 8-16, 2016.

[20] M. Hamdan, N. Alharbi, "The Effectiveness of Semantic Mapping Strategy on Vocabulary Achievement of EFL Saudi Female Preparatory-Year Students,". Journal of Applied Linguistics and Language Research, 4 (7). PP. 14-46, 2017.

[21] A. Kaveh, E. Rassaei, "The Effect of Concept Mapping on Iranian EFL Learners' Vocabulary Learning and Strategy Use," Journal of Studies in Learning and Teaching English, 5 (1), PP. 9, 2016.

[22] L. Karimi, A. Heidari, "The Effect of Mind Mapping on Vocabulary Learning and Retention. International Journal of Educational Investigations," 2 (12), PP. 54-72, 2015.

[23] T. Krasnic, How to Study with Mind Maps: Concise Learning Method, Concise books publishing: LLC, 2011.

[24] R. J. Lamberski "A comprehensive and critical review of the methodology and findings in color investigations. Syracuse", NY: ERIC, 1980.

[25] A. Leyden, "10 Mind-Mapping Strategies for Teachers", 2014. [Online]. Available: http://www.teachthought.com/teaching/10mind-mapping-strategies-for-teachers

[Accessed: DEC. 12, 2018].

[26] E. Liach, B. Gallego, Teaching Visual Literacy: Using comic books, graphic novels, anime, cartoons, and more to develop comprehension and thinking skills. Thousand Oaks, Corwin Press, 2009.

[27] Y. J. Lee, "The Process-Oriented ESL Writing Assessment: Promises and Challenges," Journal of Second Language Writing, 15, PP. 307-330, 2006.

[28] I. S. P. Nation, Learning Vocabulary in Another Language, Cambridge University Press, PP.4, 2001.

[29] T .J. Nodoushan, \& Maibodi, A. H. " The Impact of Mind Mapping Strategy on Vocabulary Use in the Writing of Iranian EFL Learners", 2017. [Online]. Available: Aug 8, 2018, from https://www.researchgate.net/.../31858373 4_The_Impact_of_Mind_Mapping_Strateg y.

[Accessed: Sept 21, 2018].

[30] B., Nong, T. A. Pham, T. N. M. Tran, "Integrate the digital mind mapping into teaching and learning Psychology," Teacher Training component-ICT, VVOB. Education Program, Vietnam. 2009

[31] C. O'Reilly, “Mind Mapping: Overcoming Problems of Writer Identity and Convention for Academic Writing by Student Collaboration,". The All Ireland Journal of Teaching and Learning in Higher Education 7 (3). PP. 84- 98, 2015.

[32] S. Rabeka, "Mind Map and Brainstorm Templates. (Unpublished Master's Thesis). Seattle: Seattle University, 2014.

[33] M. F. Ruffini, "Using E-Maps to Organize Navigate Web-Based Conten," Interactive Educational Multimedia, 16, PP. 87-98, 2008.

[34] A. Bahadori, B. Gorjian, "Developing EFL Learner's Vocabulary at the PreIntermediate Level," Journal of Applied Linguistics and Language Learning, 2 (1), PP. 8-16, 9, 2016.

[35] J. Sahrawi, "The Effectiveness of Mind Mapping for Teaching Vocabulary to the Eighth Grade Students of SMP Negeri Sungai kakapo in Academic," Journal Pendidikan Bahasa, 2 (2), PP. 263- 247, 2013. 
[36] H. Toi, "Research on How Mind Map Improves Memory," Paper presented at the International Conference on Thinking, 2009.

[37] N. Wafi, "Effectiveness of Using Animated Pictures Program in Learning English Vocabulary among the Fifth Graders in Gaza". (Unpublished MA Thesis). Islamic University, Gaza, Palestine, 2013.

[38] [38] P. Siriphanich,\& C. Laohawiriyanon, "Using Mind Mapping Technique to Improve Reading Comprehension Ability of Thai EFL University Students," A paper presented in the 2nd International Conference on Humanities and Social Sciences., 2011. [Accessed May 29, 2018] http://fs.libarts.psu.ac.th/research/conferen ce/Proce edings $2 /$ article/4pdf/001.pdf

[39] M. Lipson, K. Wixson, "Assessment and instruction of reading and writing difficulties," an interactive approach, 4th Edition, Pearson Boston, 2009. 